\title{
KAWASAN KAUMAN MENARA KUDUS SEBAGAI CAGAR BUDAYA ISLAM: CATATAN TERHADAP KEBIJAKAN PEMERINTAH KABUPATEN KUDUS
}

\section{Kauman Area in Kudus as an Islamic Heritage Site: Notes on Kudus Regional Government's Policies}

\author{
Moh Rosyid \\ Institut Agama Islam Negeri Kudus \\ Jalan Conge, Ngembalrejo, Bae, Kudus, Jawa Tengah \\ E-mail :mrosyid72@yahoo.co.id \\ Naskah diterima 2 Maret 2018 - Revisi terakhir 23 Juni 2018 \\ Disetujui terbit 15 Juli 2018 - Tersedia secara online 1 Agustus 2018
}

\begin{abstract}
This article discusses about the policy of Kudus regional government concerning the preservation of heritage site of Kauman Kudus by applying historical approach. This paper aims to explain about how the local government's approaches to preserve Islamic heritage site of Kauman and how the government may improve the site. The problem of this research was to explore ehether there are any real efforts put in by the government of Kudus to preserve region of Kauman Kudus Tower area and wheteher further effort to revitalize that area as cultural heritage. The purpose of the research was to describe efforts that has been done by the government to maintain the heritage. Result showed that the local government policies related to the preservation of Kauman area focuses on the revitalizing the site such as: clearing out the main street of cars, managing souvenir dealers, documenting history of Sunan Kudus, establishing a museum of Islamic history, and forming a committee of heritage site.
\end{abstract}

Keywords: Kauman Kudus, heritage, government's policies

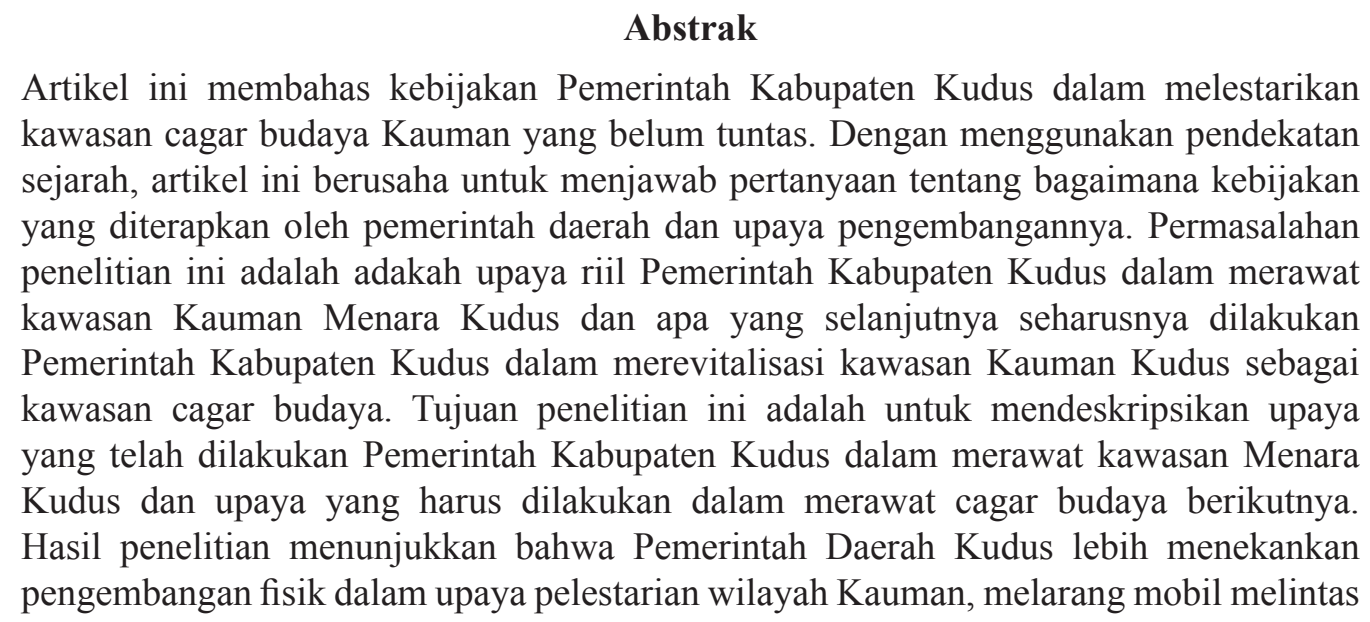


di depan Masjid Menara, dan menata pedagang cenderamata. Hal yang perlu dilakukan lainnya adalah membangun museum sejarah Islam, mendokumentasikan cerita rakyat tentang Islamisasi Sunan Kudus, serta membentuk komite cagar budaya.

Kata kunci: Kauman, cagar budaya, kebijakan pemerintah

\section{PENDAHULUAN}

Di Kota Kudus Jawa Tengah terdapat peninggalan bersejarah Islam berupa kawasan Kauman Menara Kudus. Kawasan ini perlu dijadikan cagar budaya. Nugroho memilah benda cagar budaya di Kudus yang terdiri dari era prasejarah, yaitu berupa situs Patiayam di Gunung Slumprit dan Gunung Nangka, Desa Terban, Kecamatan Jekulo, situs ditemukan tahun 2005 - 2009 berupa gading gajah (stegodon), harimau (felidae), kijang (cervidae), buaya (crocodilidae), dan temuan tahun 2012 yang berupa kepala banteng (bovidae) dan kerbau (B. bobalus). Cagar budaya pada era Islam berupa Gapura Masjid Loram (Masjid Al-Makmur), Gapuran Gerbang Tajuk Menara Kudus, dan Gapura Masjid Wali Jepang. Cagar budaya pada era kolonial berupa Kawedanan Cendono di Desa Bae yang dibangun tahun 1820 pada era bupati perdana, Omah Mode, di Jalan A. Yani Nomor 38 yang dibangun tahun 1836, Pendopo Kabupaten Kudus dibangun tahun 1819, Kawedanan Tenggeles di Desa Jekulo dan Pabrik Gula Rendeng yang berdiri tahun 1840. Semua itu telah direvitalisasi (Nugroho, 2013). Selain itu, penelitian Sahar menyatakan bahwa di Kudus terdapat Masjid Al-Aqsa Menara Kudus yang terdiri dari kompleks masjid, gapura, dan pelataran. Masjid sudah direnovasi sejak era Belanda agar terselamatkan dari kehancuran meskipun kini hanya menyisakan bagian kecil struktur bangunan yang asli (Sahar, 1990).
Dalam penelitian ini subjek kajian adalah kawasan Kauman Menara Kudus di Kota Kudus (kota lama) yang merupakan gagasan baru sebagai data pentingnya merevitalisasi kawasan cagar budaya. Menurut Nurini, kota Islam di Indonesia memiliki unsur masjid jami sebagai pusat kegiatan masyarakat, ruang terbuka, dan pasar. Kampung Kauman Kudus memiliki nilai estetika (perpaduan budaya HinduIslam), nilai kemajemukan (mencerminkan budaya Hindu), dan nilai kelangkaan (hanya di Kudus) dengan masjid dan menara sebagai peninggalan Hindu (Nurini, 2011). Hal yang memperkuat perlunya revitalisasi adalah adanya tradisi khas di Kauman Menara Kudus, yakni buka luwur (kain penutup makam Sunan Kudus) dengan pembagian nasi jangkrik sebagai simbol visual sedekah dan pesan peduli terhadap sesama (Argarini, 2015). Tradisi ini berdampak positif. Interaksi sosial masyarakat Desa Kauman dengan masyarakat pendatang berjalan baik karena masyarakat pendatang antusias melestarikan berbagai kegiatan keagamaan yang berhubungan dengan tradisi ziarah di makam Sunan Kudus. Hal ini diikat oleh faktor keagamaan, ekonomi, dan tradisi (Mutmainnah, 2009). Nurjayanti dan Arya mengungkapkan akan perlunya konsep desain pola zonasi dan pola denah dengan mempertahankan elemen arsitektur Islam di kawasan Kauman Menara Kudus (Nurjayanti \& Arya, 2011).

Permasalahan pada tulisan ini adalah 
adakah upaya riil Pemerintah Kabupaten Kudus dalam merawat kawasan Kauman Menara Kudus? Apa yang seharusnya dilakukan Pemerintah Kabupaten Kudus dalam merevitalisasi kawasan Kauman Kudus sebagai kawasan cagar budaya?

Tulisan ini mempunyai dua tujuan, pertama untuk mendeskripsikan upaya yang telah dilakukan Pemerintah Kabupaten Kudus dalam merawat kawasan Menara Kudus dan yang kedua ada upaya yang harus dilakukan pada tahapan berikutnya.

Banyaknya bangunan baru dan beralihnya fungsi bangunan kuno menjadi penyebab perubahan makna benda cagar budaya. Hingga kini yang menjadi benda cagar budaya (BCB) di kawasan Menara Kudus hanya Menara Masjid Al-Aqsha

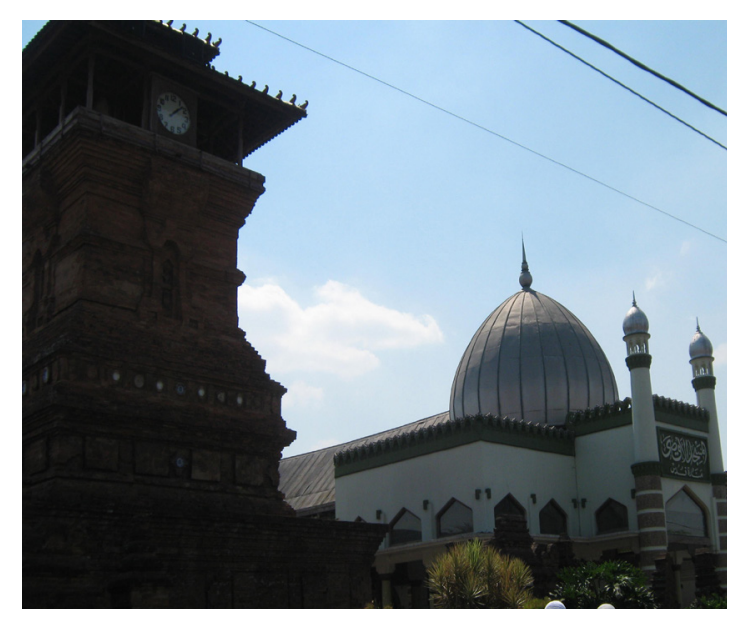

Gambar 1. Menara dan Masjid Al-Aqsha, Kudus (Sumber: M. Rosyid, 2018)

\section{METODE}

Penelitianinibertujuanmerekonstruksi masa lalu melalui tahapan heuristik, kritik, interpretasi, dan tahapan penafsiran fakta sejarah. Setelah melalui keempat tahapan tersebut kemudian dilakukan penulisan sejarah melalui proses seleksi, imajinasi, dan kronologi (Kuntowijoyo, 2008: 4). Strategi menggali sumber sejarah meliputi upaya menelusuri bibliografi, sumber sejarah primer dan sekunder, laporan umum, berita surat kabar, kuesioner tertulis, dokumen pemerintah (UU atau peraturan), sumber lisan, dan sumber lain (Wasino, 2007).

Kaidah penulisan sejarah mempertimbangkan regularitas dan konsistensi, kesamaan karakteristik tertentu, memahami pembabakan waktu sejarah, menafsirkan, mengerti, dan memahami peristiwa sejarah (Kuntowijoyo, 2001). Sejarawan setidaktidaknya mempunyai dua tujuan dalam menulis sejarah, yakni pengawal warisan budaya dan penutur kisah (Gottschalk, 1975).

Dalam penjabaran metode sejarah, penulisan ini diawali dengan penggalian data sejarah Kampung Kauman, Kudus dan tinggalan-tinggalan arkeologisnya. Langkah selanjutnya meninjau upayaupaya renovasi yang telah dilakukan. Terakhir adalah memberi masukan/ saran untuk pelestarian dan pemanfaatan Kampung Kauman, Kudus sebagai kawasan situs cagar budaya.

\section{HASIL DAN PEMBAHASAN Sejarah Kauman Kudus}

Kauman Kudus identik dengan trah kelas menengah-atas dengan mata pencaharian berdagang dan terdidik sehingga menduduki strata sosial tinggi. Kini dikenal gusjigang (gus: bagus perilakunya, ji/ngaji: belajar ilmu Islam, dan gang: berdagang). Menurut Said, 
jaringan perdagangan Kudus menjangkau hingga Tiongkok dan Vietnam (Said, 2013). Kondisi kini, Kauman Kudus berubah karena kepemilikan lahan dan bangunan bersejarah ada yang beralih/dijual pada pihak lain. Menurut Hardiansyah, rumah adat Kudus memiliki atap berbentuk tipe payon tanpa hiasan ukiran. Setelah masuknya Islam, berperan Sunan Kudus dan Kiai Telingsing, rumah adat Kudus mengadopsi kebudayaan asli Hindu, Jawa, Cina, dan Islam sehingga mengalami perpaduan bentuk ornamen (Hardiansyah, 2009). Menurut Anisa, rumah adat Kudus berbentuk tradisional, fasadnya diubah dengan pola tidak berubah dalam bentuk rumah gedong (Eropa), bangunannya ada di lingkungan Kilungan sejak 1800 - 1930 (Anisa, 2004). Rumah adat Kudus banyak yang dijual pemiliknya karena pembagian warisan. Di Kauman jumlahnya kini tidak lebih dari empat rumah adat. Menurut Said, Kampung Kudus Kuno, sejak abad ke-15 M, didasar pada toponimi, yakni perkampungan kecil di Desa Langgardalem, Kecamatan Kota, Kudus (bersebelahan dengan Desa Kauman Menara Kudus) dengan adanya sengkalan memet yang menunjukkan tahun 863 H (Said, 2010). Bangunan rumah adat Kudus memiliki tata ruang yang terdiri atas jogosatru (bagian depan), ruang dalam (inti), dan pawon (dapur). Pada halamannya ada sumur yang sebelah kirinya (pakiwon) ada kamar mandi dan padasan (untuk cuci muka) (Ekarini, 2016). Menurut Said, Rumah Adat Kudus $95 \%$ terbuat dari kayu jati (Tektona grandis) dengan konstruksi bongkarpasang (completely knock down) (Said, 2012).

\section{Jati Diri Sunan Kudus}

Sunan Kudus (Ja'far Shodiq) adalah putra dari Sunan Ngudung atau Raden Utsman Haji dengan Nyai Anom Manyuran binti Nyi Gede/Ageng Maloka (putri Sunan Ampel dengan Nyi Ageng Manila). Sunan Ngudung merupakan keturunan Arab dan pernah menjadi senopati Kerajaan Demak serta imam Masjid Agung Demak, pernah ditugaskan menyerang Majapahit pada masa pemerintahan Girindra Wardana (Brawijaya VI) (Sunyoto, 2016). Dalam catatan lain, nama kecil Sunan Kudus adalah Ja'far Shodiq, putra Sunan Udung/ Ngudung dengan Syarifah (adik Sunan Bonang), anak Nyi Ageng Maloka. Sunan Ngudung adalah seorang putra Sultan di Mesir yang berkelana hingga ke Jawa. Di Kasultanan Demak semasa dipimpin Raden Prawata, Sunan Kudus diangkat sebagai panglima perang Adipati Jipang, Arya Penangsang. Sunan Kudus berguru pada Sunan Kalijaga.

Kota Kudus (al-Quds) dibangun Sunan Kudus bersama seorang keturunan Tionghoa, The Ling-Seng. Ketika berhaji, Sunan Kudus singgah di Baitul Maqdis (Al-Quds) mendalami Islam. Sepulangnya ke Kudus, dia membawa batu prasasti berbahasa Arab tertanggal $956 \mathrm{H}$ (1549 M). Prasasti ini sekarang terpasang di mihrab Masjid Menara Kudus.

Menurut versi cerita rakyat, ketika Sunan Kudus berada di Baitul Maqdis, terjadi wabah penyakit mematikan (pageblug) yang diberantasnya. Amir Palestina (guru Sunan Kudus) memberi wewenang sebagai hadiah, yaitu menempati daerah di Palestinayang dipindahkan ke Jawa (Zamhuri, 2012). 


\section{Masjid Al-Aqsha dan Cagar Budaya}

Sunan Kudus membangun Masjid Menara saat itu bernama Loaram yang diubah menjadi Al-Manar atau Masjid Al-Aqsha, yang meniru nama masjid di Palestina. Masjid Menara Kudus mempunyai luas $1.723,84 \mathrm{~m}$ yang dibangun di lahan seluas $6.325 \mathrm{~m}$. Tahun pembangunan menara tertulis dalam candra sengkala beraksara Jawa berbunyi Gapura Rusak Ewahing Jagat: yang berarti tahun 1609 J/1687 M. Pada 5 November 1933 M dilakukan perluasan serambi Masjid AlAqsha. Renovasi pawastren (untuk salat perempuan) dilakukan tahun 2011 dan renovasi tajug dilakukan tahun 2013.

Objek purbakala di lingkungan masjid berupa (1) dua gapura kembar gaya Hindu di serambi luar dan di dalam masjid (awalnya benteng pelindung masjid era kewalian), gapura padureksan (di luar masjid), gapura samping masjid, dan gapura tajug (sisi samping belakang masjid). Gapura kembar bagian dalam merupakan pintu masuk masjid. Terdapat menara bahan bangunannya batu bata merah, sirap, dan perekat batu bata dengan susunan selasar batu, kaki, tubuh bangunan, dan atap. Pada bagian kaki (dasar) menara terdapat ornamen geometrik berupa batu hiasan segi empat yang setiap ujungnya disambung hiasan segi tiga. Bentuk gapura serupa dengan pura. Menurut Pradisa, melekatnya budaya Hindu yang diadaptasi pada budaya Islam membentuk perpaduan budaya yang unik antara budaya Islam dengan Hindu (Pradisa, 2017), (Lihat Lampiran Gambar 3); (2) tempat wudlu (padasan) yang terdiri atas delapan pancuran (kran) hingga kini masih utuh; (3) tajug, tempat musyawarah
Sunan Kudus (pada masa kini, khususnya bulan Ramadan, digunakan untuk mengaji kitab kuning pada sore hari) dan tempat menyimpan keris serta tombak Sunan Kudus dalam peti.

\section{Renovasi Menara Kudus}

Bentuk menara merupakan hasil akulturasi budaya Hindu dengan Islam. Tinggi menara 17/18 $\mathrm{m}$ dan luas 100 $\mathrm{m}^{2}$. Pada era Sunan Kudus, menara digunakan muadzin untuk adzan salat. Menurut Munoz, candi merupakan sarana yang digunakan Raja Jawa dalam memertahankan kekuasaannya sehingga pembangunannya bersifat politis daripada religius. Candi juga menguatkan kekuasaan politik penguasanya (Munoz, 2009). Sebutan candi digunakan orang Jawa Tengah, masyarakat Sumatra menyebutnya biaro, warga Jawa Timur menyebut cungkup, yaitu tempat dewa dapat membuat dirinya "tampak" dengan desain candi itu sendiri (Tim Museum Ronggowarsito, 2004). Menara masjid berdasarkan inskripsi Arab Kuno (yang ada di mihrab Masjid Al-Aqsa) keberadaannya lebih dulu ada jika dibandingkan dengan masjid. Masjid didirikan tahun 956 H/1549 M dengan nama Masjid Al-Manar atau AlAqsa yang pernah direnovasi pada 1919, 1933, 1976, dan 1978. Masjid Menara Kudus seluas 1.723,84 $\mathrm{m}^{2}$ di lahan seluas $6.325 \mathrm{~m}^{2}$, terdapat dua gapura kembar gaya Hindu di serambi luar. Awalnya gapura merupakan benteng pelindung masjid di era wali. Panjangnya $548 \mathrm{~cm}$, lebar 272 $\mathrm{cm}$, tinggi $625 \mathrm{~cm}$, lebar pintu $116 \mathrm{~cm}$, dan tinggi pintu $271 \mathrm{~cm}$. Gapura kembar bagian dalam merupakan pintu masuk masjid. Juga terdapat menara berukuran 10 
$\mathrm{m}$, tinggi $18 \mathrm{~m}$, bahan bangunannya dari batu bata merah, sirap, dan perekat batu bata dengan susunan selasar batu, kaki, tubuh bangunan dan atap. Pada bagian kaki (dasar) menara terdapat ornamen geometrik yang berupa batu hiasan segi empat yang setiap ujungnya disambung hiasan segi tiga.

Dalam cerita rakyat Kudus, Menara Kudus, sebelum datangnya Islam di Jawa, mempunyai beberapa tafsiran, yaitu (1) tempat pembakaran mayat para raja atau kaum bangsawan Hindu, (2) bekas candi Hindu, bangunan candi yang menyerupai candi Singosari dan candi Kidal di Jawa Timur.

Di titik bangunan Menara Kudus sebelumnya ada sumber air kembar yang memancarkan air (banyu kauripan atau amarta/tirta kamandanu). Masyarakat Kudus saat itu meyakini bahwa air dapat menghidupkan orang yang mati sehingga mengganggu akidah, yang akhirnya sumber air tersebut ditutup dan didirikannya Menara Kudus (Salam, 1986).

Menara memiliki pernik yang tertempel yang berupa keramik. Sakai Takashi dan Takimoto Tadashi, arkeolog Jepang, menelusuri asal mula berbagai keramik di Masjid dan Menara Kudus. Menurutnya, dua di antara sekian banyak keramik adalah buatan pabrik keramik di Vietnam abad ke-14 - 15 (Said, 2013).

Sejak tahun 1980, pengelolaan kawasan Menara Kudus dilakukan oleh Yayasan Masjid, Menara, dan Makam Sunan Kudus (YM3SK) yang sebelumnya ditangani Takmir Masjid Menara Kudus.

Rehabilitasi Menara Kudus bagian tembok menara dilakukan tahun 1880 , 1913, dan 2014. Adapun rehab selasar menara dilakukan tahun 1933. Tim Balai Pelestarian Cagar Budaya (BPCB) Jawa Tengah, pada tahun 2014, memugar Menara Masjid Al-Aqsha Kudus dan melanjutkan pemugaran tahun 2011. Pemugaran pada 2013 dilakukan bagian mustaka atau atap serta sirap dan mengganti 3.000 buah batu bata yang rapuh di 28 lapis. Pemugaran pada Mei 2014 merevitalisasi batu bata yang $80 \%$ rapuh diganti yang diganti baru. Terdapat 10 ribu batu bata yang diganti karena rapuh. Teknik penggantian dilakukan secara konvensional, yakni melepas satu per satu agar tidak mengganggu konstruksi. Pengerjaan dengan pola konsolidasi, yakni dari atas ke bawah karena medan yang sulit dan untuk kenyamanan peziarah. Untuk batu batu, relief yang klasik dan kondisinya rusak atau hilang dilakukan repro agar tidak menghilangkan nilai sejarah. Hasil temuan Tim BPCB Jateng dalam pemugaran Menara Kudus menyebutkan bahwa penyebab kerusakan konstruksi menara adalah getaran kendaraan bermotor yang melintas di depan menara. Koordinator pemugaran Menara dari BPCB Jateng, Rabiman, mengatakan bahwa dilakukan penggantian batu bata menara yang sudah rapuh dan pembuatan peredam getaran di bawah samping fondasi ("Pemugaran Menara Kudus," 2014). Jaraknya selebar satu meter, digali, dan diberi batu kali dengan cor semen. Salah satu sudut konstruksi yang paling parah berada di sebelah timur yang letaknya berdekatan dengan akses jalan. Menurut tim, di sekitar Menara Kudus idealnya tidak diperkenankan dilewati kendaraan bermotor karena menimbulkan 
getaran. Pada Juni 2014 dipugar tubuh menara bagian tengah hingga ke bawah, yakni mengganti 10.000 batang batu bata yang rapuh secara konvensional; menempelkannya dengan mencampur pecahan batu bata yang dilembutkan dan gamping untuk menghindari efek penggaraman dari semen. Kondisi menara terparah terdapat pada bagian tubuh di sebelah timur dengan tingkat kerusakan mencapai $60 \%$ karena getaran kendaraan yang lalu lalang. Menara Kudus telah berumur 500 tahun sehingga disiapkan 10.000 bata yang bentuk dan kualitasnya mirip dengan batu bata aslinya yang terpasang. Batu bata baru itu dipesan di Desa Pasuruan, Kecamatan Jati, Kudus yang terbuat dari tanah lempung asli tanpa campuran dengan ukuran panjang $31 \mathrm{~cm}$, lebar $15 \mathrm{~cm}$, dan tebal $5 \mathrm{~cm}$. Biaya pemugaran berasal dari APBN tahun 2013, yaitu sebesar Rp 419.469 juta. Anggaran APBN tahun 2014, yaitu sebesar Rp 300 juta. Ornamen Menara Kudus berbentuk piring, terbuat dari bahan keramik yang sebagian sudah tidak ada di tempat semula karena terlepas, tetapi juga ada yang masih menempel. Pada pemugaran tahun 1980-an ada yang ornamen dipasang tidak sesuai dengan posisi aslinya. Metode pemasangan ornamen dilakukan dengan adonan nonsemen agar tidak terjadi penggaraman. Setelah sebulan pembongkaran, pada akhir Juni 2014 puluhan ribu batu bata Menara Kudus diganti. Pada fase ini tim menghadapi masa sulit karena kondisi material (bata) lama mengalami tingkat kerusakannya cukup parah jika dibandingkan dengan bagian sebelumnya yang telah dipugar. Batu bata lama yang ukurannya sudah tidak beraturan dan banyak yang rapuh harus disusun lagi sebagaimana sediakala. Jika tidak berhati-hati, hal itu akan mengganggu konstruksi menara. Melepas batu bata lama dilakukan dengan metode konvensional, yakni melepas satu per satu dari badan menara. Begitu pula ketika menggantinya dengan batu bata yang baru. Memotong dengan menggunakan mesin pemotong dilakukan untuk efesiensi waktu dan hasilnya lebih bagus. Kendala yang dihadapi tim adalah ukuran batu bata yang akan digunakan mengganti bata lama tidak pas sehingga diganti yang lebih tebal. Semula tebalnya $4,5 \mathrm{~cm}$ dan diganti dengan $7 \mathrm{~cm}$. Pemugaran Menara Kudus pada tahun 2002 dan April 2014 melibatkan 20-an pekerja dari tim Balai Pelestarian Peninggalan Purbakala (BP3) Jawa Tengah. Tingkat kerusakan Menara Kudus mencapai $90 \%$, terutama pada tubuh bangunan yang menghadap ke timur yang sudah lapuk dan rusak. Menurut juru pugar dari BPCB Jawa Tengah, kerusakan terjadi akibat getaran kendaraan bermotor yang lalu lalang, faktor cuaca berupa sinar matahari, dan guyuran air hujan yang prosesnya terakumulasi sehingga membuat material mudah rusak. Langkah yang dilakukan adalah melepas semua batu bata di bagian kaki tubuh bangunan menara, mulai dari trap (undakan) pertama hingga terap ketiga. Pemugaran Menara Kudus pada Juni 2014 mencapai 40 $\%$, sebagian dari tubuh Menara Kudus menggunakan material baru. Hal itu tidak menghilangkan nilai sejarah karena tidak menghilangkan atau menambah bagian pada Benda Cagar Budaya ("Pemugaran Menara Kudus,” 2014).

Fondasi Menara Kudus dipugar sebelum tahun 1980-an untuk 
menempatkan cor beton dengan kedalaman $50 \mathrm{~cm}$ sebagai penahan air agar tidak merembes ke bagian fondasi bawah yang masih menggunakan batu-bata. Menurut Tim BPCB Jateng, hasil penggalian fondasi pada September 2014 adalah di sebelah selatan bangunan kedalaman fondasinya $190 \mathrm{~cm}$, terdiri atas 30 lapis batu bata. Sebelah utara sisi barat ukuran kedalaman fondasinya sama dengan sebelah selatan. Kedalaman fondasi gapura $80 \mathrm{~cm}$ dan fondasi pagar 1,5 m. Rata-rata fondasi hingga September 2014 masih normal dan tidak ada masalah. Hingga September 2014, pemugaran Menara Masjid AlManar Kudus mencapai $80 \%$ dari target $100 \%$ pada akhir 2014. Memasuki bagian akhir pemugaran, tim BPCB Jateng mengembalikan ornamen ukiran di bagian barat atau tepatnya di kanan dan kiri tangga menara. Begitu pula penyelesaian selasar bangunan dan konservasi (pemeliharaan) bagian atas menara atau pilar penyangga atap yang berbahan material kayu. Bagian tubuh menara disemprot dengan zat antilumut, untuk bagian atas diberi cairan berbahan dari rebusan tembakau dan cengkih, kemudian dikuaskan pada empat pilar penyangga atap serta bagian lain yang berbahan material batu. Tujuannya ialah agar material lama dan yang baru (pengganti) lebih awet dan tahan lama. Pada minggu ketiga, September 2014, dilakukan pelepasan andang (penyangga dari bambu yang sebelumnya digunakan sebagai alat bantu memanjat untuk memugar bagian tubuh menara) dalam proses renovasi. Pada awal Oktober 2014 pemugaran diselesaikan secara menyeluruh. Pada pertengahan Oktober 2014 pemugaran selesai. Kurang lebih 10 ornamen yang menempel di tubuh menara, yaitu berupa piring keramik kuno, dipasang pada tempat semula agar keaslian benda cagar budaya itu tetap terjaga. Adapun ornamen yang rusak diganti dengan ornamen yang mirip tanpa mengubah bentuk agar tetap utuh tanpa menghilangkan keaslian. Keramik piring buatan Maastricht Belanda diperoleh Yayasan Masjid, Menara, dan Makam Sunan Kudus (YM3SK) dari pihak lain untuk melengkapi ornamen yang hilang meskipun warna piringnya kuning kecoklatan, tidak sama dengan aslinya, yakni biru. Piring keramik berukuran besar, jumlahnya 20 buah, yang kecil 21 buah dan kurang satu yang akhirnya dilengkapi. Untuk menjaga bangunan menara, dibatasi

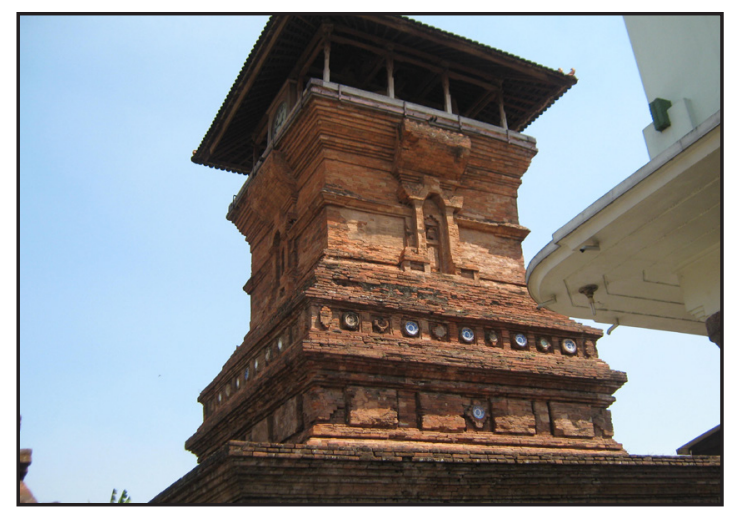

Gambar 2. Menara Masjid Al-Aqsha, Kudus (Sumber: M. Rosyid, 2018)

kunjungan bagi wisatawan yang naik ke atas bangunan Menara Kudus, terutama bagian paling atas kepala menara. Hal ini, menurut BPCB Jateng, sebagian besar materialnya terbuat dari kayu, bukan dari batu andesit atau batu bata sehingga rentan rusak. Sebelum pemugaran pada September - Oktober 2014, ada 4 pilar

penyangga mustaka yang kondisinya miring $11 \mathrm{~cm}$ ke barat, setelah dipugar bisa kembali seperti semula. Agar kondisi 
material kayu di bagian atas Menara Kudus tidak bergeser dari tempatnya, diberi pengikat pelat besi agar kuat. Konstruksi penyangga pilar dan material kayu hanya disatukan, tidak permanen, tetapi knock down dapat dibongkar dan pasang. Oleh karena itu, perlu kehati-hatian saat naik bagian atas.

\section{Renovasi Makam Sunan Kudus}

Pada kompleks bagian belakang Masjid Menara terdapat makam Sunan Kudus, keluarga, dan pasukannya. Panjang makam sang Sunan $225 \mathrm{~cm}$, lebarnya 70 $\mathrm{cm}$, dan tingginya $40 \mathrm{~cm}$, tinggi batu nisan $68 \mathrm{~cm}$, lebar $14 \mathrm{~cm}$. Terdapat delapan cungkup atau bangunan pelindung makam di kompleks pemakaman Sunan Kudus yang direstorasi (dikembalikan sesuai dengan aslinya) dengan material baru. Adapun umpak semula diganti dengan cor semen, pada Agustus 2014 diganti dengan

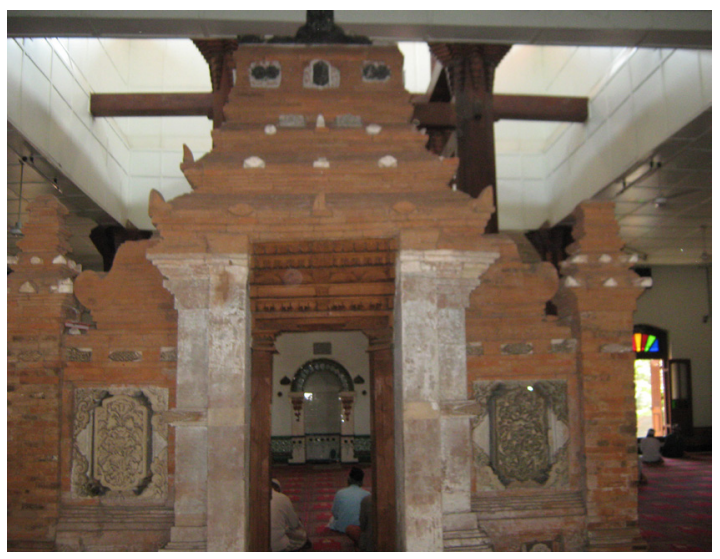

Gambar 3. Gapura/Pintu Kuno Masuk Masjid berada di dalam Masjid Al-Aqsha Menara Kudus (Sumber: M. Rosyid, 2018)

batu andesit, sebagaimana awalnya dan untuk lantai di makam dipesankan. Ada pula tiga tajuk yang beratap sirab (genting terbuat dari kayu) berbentuk kotak memanjang dan lonjong di kompleks Masjid dan Makam Sunan Kudus. Dalam merenovasi sirab, Yayasan Masjid Menara dan Makam Sunan Kudus (YM3SK) mengembalikan bentuk asli pascarenovasi dengan memesan sirab khusus dari Kebumen Jateng yang berbahan tanah (genting). Dalam tajuk terdapat lamber siring, blandartakir, dan sunduk yang terbuat dari kayu jati. Bahkan, sunduk dibuat dari kayu utuh sepanjang $8 \mathrm{~m}$.

Kompleks Makam Sunan Kudus terpilah tiga blok, yaitu sebagai berikut. (1) Keluarga Sunan Kudus, yang terdiri atas putra Sunan Kudus dengan isteri keduanya (Adipati Pecat Tanda Terung, putri Pangeran Husen, seibu dengan Raden Patah dari Majapahit) yang dikaruniai 8 anak. Makam kedelapan putra Sunan Kudus yang ada di kompleks Sunan Kudus hanyalah empat, yakni Panembahan Palembang, Panembahan Mekaos Honggokusumo, Pangeran Poncowati, dan Pangeran Sujoko (wafat masih muda). Adapun yang tidak terdeteksi selingkungan dengan makam Sunan Kudus, yakni Nyi Ageng Pembayun, Panembahan Kodhi, Panembahan Karimun, Pangeran/ Ratu Probobinabar (panglima perang), Panembahan Kuleco, dan Ratu Pakojo (Salam, 1986), (2) Kompleks orang dekat Sunan Kudus, yakni Pangeran Pedamaran I sampai dengan V, dan (3) kompleks pejabat tinggi di Kudus era pra dan masa Orde Lama, yakni K.H.R Padmonegoro (mantan Bupati Kudus, menantu Susuhunan Paku Buwono III era 1749 - 1788), R. Ayu Tjondrohadinegoro, R. Ayu Tisnowijoyo Patih Tumenggung, K.R.T Tjokrohadinegoro, R. Ayu Ng. Sumodiprojo, R.M. Pratisna Suryakusumo, 
R. Bagus Sutikna Tjokronegoro, Penghulu Bedogas, dan lain-lain (Salam, 1977).

BPCB Jawa Tengah pada Desember 2014 melakukan supervisi, pengawasan, dan pendampingan konservasi kawasan kompleks Makam Sunan Kudus yang memerlukan perbaikan. Kegiatan tersebut di antaranya pembenahan pagar Makam Sunan Kudus dengan cara mengurangi ketinggian pagar sebanyak dua lapis batu bata agar sirkulasi udara terjaga terutama saat jumlah peziarah meningkat; Pembenahan atap makam yang lapuk dilakukan dengan cara menggantinya dengan terakota sesuai aslinya; dan pembenahan nisan makam yang rusak dengan tidak mengubah bentuk aslinya yang rata-rata berukuran besar. Bahan yang digunakan untuk mengganti berupa batu bata dari Jatirogo Jatim.

\section{Upaya Pemda Kudus dalam Merawat Kawasan Kauman Menara Kudus}

Pemerintah Kabupaten Kudus merevitalisasi kawasan alun-alun lama Kudus (disebut Taman Menara Kudus atau Taman Beringin). Pembangunan kawasan taman dengan memindahkan pangkalan angkutan umum, parkir mobil peziarah, ojek sepeda motor, dan becak ke tempat lain. Melalui pemindahan tersebut diharapkan ojek dan becak tidak lagi melewati jalan di depan Menara Kudus sebagai upaya mengurangi kepadatan lalu lintas dan mengurangi getaran yang mengganggu bangunan menara.

Ciri khas alun-alun lama kawasan Menara masih dipertahankan, yakni sebatang pohon beringin di tengah-tengah taman, pemilah antara Masjid Madureksan (dibangun pra-Masjid Menara Kudus) dengan Kelenteng Hok Ling Bio.

\section{Urgensi Pelestarian Cagar Budaya Ka- wasan Kauman Menara Kudus}

Bangunan Masjid Al Aqsa Kudus, menurut Aisy, memiliki karakter visual, yakni keseluruhan elemen yang membentuk fasade eksterior dan interior berupa gaya bangunan, pintu, jendela, dan dinding. Karakter spasial meliputi tata ruang dan orientasi bangunan dan strukturnya. Aisy merekomendasikan bahwa arah pelestarian harus sesuai dengan elemen bangunan masjid (Aisy, n.d.). Ciri khas Menara Kudus, ornamennya bercorak Islami yang mengalami denaturalisasi, yakni menyembunyikan tampilan bentuk natural sehingga terlihat seperti benda alam yang merupakan kesinambungan gaya pra-Islam (Supatmo, 2014).

Program revitalisasi bangunan Menara Kudus yang dilakukan, adalah pertama, sepanjang Jalan Menara (jalan raya di depan Menara Kudus) tidak lagi dapat dilalui kendaraan angkutan umum dan kendaraan roda empat atau lebih lainnya, kecuali penghuni. Berdasarkan fakta, pada Juni 2014 dipugar tubuh menara bagian tengah hingga ke bawah, yakni mengganti 10.000 batang batu bata yang rapuh dengan cara konvensional. Kondisi menara terparah ada di bagian tubuh di sebelah timur, tingkat kerusakannya mencapai 60 $\%$ yang disebabkan oleh getaran lalu lalang kendaraan. Guna mengurangi dampak dari getaran kendaraan, Tim BPCB Jawa Tengah pada 30 Mei 2014 memasang peredam getaran di sekeliling fondasi menara dengan panjang $1 \mathrm{~m}$ dan kedalaman 1,5 m. Pemasangan dilakukan dengan teknik tradisional, yakni memasang batu 
kali, batu kerikil, dan pasir dengan adonan (dicampur) semen (model arsitek tempo dulu). Sebagai perekat kombinasi material tersebut digunakan adonan tumbukan batu bata merah, pasir, dan gamping. Guna menjaga ketahanan menara dari gempa, BPCB Jawa Tengah memasang sabut kelapa dan ijuk di bagian blok kayu. Upaya yang telah dilakukan tersebut akan sia-sia jika kendaraan bermotor tetap diijinkan melintas di depan Menara Kudus.

Kedua, memindahkan bangunan rumah dan toko milik warga yang memisahkan antara alun-alun lama (taman kota) dengan Masjid Al-Aqsha dengan pola ganti untung. Belasan ruko dibangun tahun 1926 dan menghalangi pemandangan antara Masjid Al-Aqsha, Menara Kudus, Masjid Madureksan, alunalun lama (taman kota), dan Kelenteng Hok Ling Bio. Ketiga, didirikan museum agar peristiwa masa lalu terdokumentasikan dan sebagai tempat penyimpanan bendabenda peninggalan masa lalu, seperti keris Kiai Cinthaka, dan tombak kembar.

Keempat, dibentuk tim ahli CB berdasarkan Undang-undang No. 11 Th. 2010. Kelima, melakukan identifikasi dan revitalisasi peninggalan Sunan Kudus, seperti dugaan bangunan rumah Sunan Kudus di sekitar Masjid Langgar Dalem (di Kampung Langgar Dalem) yang hingga kini belum jelas, sumur resapan era Sunan Kudus di pawestren (tempat salat di sebelah kanan Masjid Menara untuk perempuan yang berjamaah).

Upaya tersebut harus dilakukan oleh Pemerintah Daerah Kabupaten Kudus bekerja sama dengan Yayasan Menara Kudus, karena benda sejarah merupakan cagar budaya dan kekayaan budaya bangsa yang penting bagi pemahaman dan pengembangan sejarah, ilmu pengetahuan, dan kebudayaan. Upaya perlindungan, pengembangan, dan pemanfaatan harus dilakukan dalam rangka memajukan kebudayaan nasional untuk kemakmuran rakyat. Untuk melestarikan cagar budaya (CB), Pemda bertanggung jawab dalam pengaturan perlindungan, pengembangan, dan pemanfaatannya. Cagar Budaya berupa benda, bangunan, struktur, situs, dan kawasan perlu dikelola oleh pemerintah serta meningkatkan peran serta masyarakat untuk melindungi, mengembangkan, dan memanfaatkannya.

Jika museum khusus yang menyimpan benda Cagar Budaya berbasis Islam terwujud, ikon kota santri bagi Kudus kian kokoh. Ikon kota sangat penting bagi pencitraan kota Kudus yang saat ini lebih identik sebagai kota kretek, bukan sebagai kota santri.

Kekhasan kota di antaranya dengan dibangunnya simbol kota. Kemegahan kota ditentukan oleh banyaknya situs bersejarah yang dirawat hingga direspons wisatawan untuk dikunjungi. Kriteria kota ideal, yaitu aman, nyaman, kompetitif, dan layak huni terwujud dan untuk mewujudkan kota ekowisata didukung potensi local, berupa sumber daya alam, sosial ekonomi, dan tradisi khas yang unik.

Peluang mewujudkan Kauman sebagai kawasan $\mathrm{CB}$ yang dijadikan heritagecity (kota warisan budaya) diawali dengan merevitalisasi kawasan Kauman Menara Kudus. Upaya tersebut memerlukan biaya besar jika memindah rumah penduduk di kawasan Menara Kudus. Di sisi lain, umur kawasan menara sudahkah 500 tahun. Padahal, bangunan 
asli masjid Sunan Kudus sudah tidak ada, kini semuanya hasil rehab. Langkah awal bagi Pemda Kudus adalah membahas dengan Pengurus Yayasan Masjid dan Menara Kudus serta warga Kudus untuk mencari solusi bijak dengan melibatkan sejarawan, arkeolog, tokoh agama, dan masyarakat Kudus.

\section{SIMPULAN}

Kota yang ideal adalah jika terwujud kondisi aman, nyaman, kompetitif, dan layak huni. Hal ini merupakan modal untuk dijadikan sebagai kota ideal dan kota ekowisata untuk menambah income daerah dan warga di bidang pariwisata. Upaya Pemerintah Kabupaten Kudus dengan merevitalisasi Taman Beringin yang merupakan bagian dari kawasan Kauman Kudus perlu ditindaklanjuti dengan upaya lain. Pertama, melarang mobil/ roda empat atau lebih, becak, delman, dan angkutan sejenis melewati/melalui Jalan Menara (jalan di depan bangunan Menara Kudus) Kedua, memindahkan bangunan rumah dan toko (ruko) warga yang berada di antara alun-alun lama Menara (taman kota) dengan Masjid Al-Aqsha. Ketiga, membangun museum Islam agar dokumen dan karya budaya keislaman yang diwariskan Sunan Kudus dan Sunan Muria terawat. Keempat, dibentuk tim ahli Cagar Budaya, tenaga ahli pelestarian dan kurator, sebagaimana amanat Undangundang No. 11 Th. 2010 tentang Cagar Budaya. Kelima, mendokumentasikan cerita rakyat yang memuat Islamisasi Sunan Kudus.

\section{DAFTAR PUSTAKA}

Aisy, R. A. (n.d.). Pelestarian Bangunan Masjid Al Aqsa Manarat Qudus Jawa Tengah. Malang.

Anisa. (2004). Rumah dalam Kilungan di Kota Lama Kudus: Analisis Konsep dan Susunan Bangunan dalam Kilungan. Jurnal Nalars, 3(1), 1-17.

Argarini, M. (2015). Persepsi Masyarakat Kudus terhadap Tradisi Bukaluwur Sunan Kudus. Universitas Nasional Surakarta.

Ekarini, D. (2016). Dilema Pelestarian Rumah Adat Kudus. Jurnal Konservasi Cagar Budaya Borobudur, 10(1), 1-15.

Gottschalk, L. (1975). Mengerti Sejarah. Jakarta: Universitas Indonesia Press.

Hardiansyah, M. (2009). Rumah Tradisional Kudus: Pengaruh Budaya Islam (15001900). Universitas Islam Nusantara Jakarta.

Kuntowijoyo. (2001). Pengantar Ilmu Sejarah. Yogyakarta: Bentang.

Kuntowijoyo. (2008). Paradigma Islam: Interpretasi untuk Aksi. Bandung: Mizan.

Munoz, P. M. (2009). Kerajaan-Kerajaan Awal Kepulauan Indonesia dan Semenanjung Malaysia. Yogyakarta: Mitra Abadi.

Mutmainnah. (2009). Interaksi Sosial Masyarakat Desa Kauman dengan Masyarakat Pendatang dalam Tradisi Ziarah di Makam Sunan Kudus. Universitas Islam Nusantara, Sunan Kalijaga.

Nugroho, A. (2013). Revitalisasi Bangunan Cagar Budaya Kabupaten Kudus tahun 2005-2010. Universitas Negeri Semarang. 
Nurini, N. (2011). Kajian Pelestarian Kampung Kauman Kudus sebagai Kawasan Bersejarah Penyebaran Agama Islam. Jurnal Teknik Fakultas Teknik Undip, 32(1), $11-22$.

Nurjayanti, W., \& Arya, R. (2011). Rekayasa Disain Rumah Islami Berdasar Studi Eksplorasi pada Pemukiman di Kompleks Masjid Menara Kudus. Surakarta.

Pemugaran Menara Kudus. (2014). Suara Merdeka, p. 4.

Pradisa, A. P. (2017). Perpaduan Budaya Islam dan Hindu dalam Masjid Menara Kudus. Cirebon.

Sahar, S. (1990). Dimensi-Dimensi Renovasi Masjid Menara Kudus. Universitas Gajah Mada.

Said, N. (2010). Jejak Perjuangan Sunan Kudus dalam Membangun Karakter Bangsa. Kudus: Brilian Media Utama.

Said, N. (2012). Tradisi Penidikan Karakter dalam Keluarga Tafsir Sosial Rumah Adat Kudus. Kudus: Brilian Media Utama.

Said, N. (2013). Filosofi Menara Kudus Pesan Damai untuk Dunia. Kudus: Brilian Media Utama.

Salam, S. (1977). Kudus Purbakala dalam Perjuangan Islam. Kudus: Menara Kudus.

Salam, S. (1986). Ja'far Shodiq Sunan Kudus (3rd ed.). Kudus: Menara Kudus.

Sunyoto, A. (2016). Atlas Wali Songo. Jakarta: Pustaka Ilman dan Lesbumi PBNU.

Supatmo. (2014). Keunikan Ornamen Bermotif Figuratif pada Kompleks Bangunan Masjid Menara Kudus. Laporan Penelitian, 8(1), 20-31.

Tim Museum Ronggowarsito. (2004). Artefak Batu Masa Prasejarah-Hindu Buddha (Koleksi Museum Jawa Twngah Ronggowarsito). Semarang: Pemerintah Propinsi Jawa Tengah.

Wasino. (2007). Dari Riset Hingga Tulisan Sejarah. Semarang: Universitas Negeri Semarang Press.

Zamhuri. (2012). Sunan Muria dan Sunan Kudus Prinsip Hidup dalam Membentuk Karakter Bangsa. Kudus: Badan Penerbit Muria Kudus. 